WEDNESDAY, 14 JUNE 2017

\section{Impact of rheumatic diseases}

\section{OP0064 CLEFS DE DOS: A UNIQUE PARE-LED VIDEO PROGRAM TO IMPROVE COPING SKILLS OF PEOPLE LIVING WITH AXIAL SPONDYLOARTHRITIS}

C. Beauvais ${ }^{1}$, C. Sordet ${ }^{2}$, A. Leboime ${ }^{3}$, D. Vandame ${ }^{4}$, C. Saadoun ${ }^{4}$, G. Genin ${ }^{5}$, F. Gerald ${ }^{6} .{ }^{1}$ Hôpital Saint Antoine, Paris; ${ }^{2} \mathrm{CHU}$ de Strasbourg, Strasbourg;

${ }^{3}$ Hôpital Amboise-Paré, Paris; ${ }^{4}$ UCB Pharma, Colombes; ${ }^{5}$ Agence Catalpa,

Paris; ${ }^{6}$ Association Action contre les Spondylarthropathies - ACS, Nice, France

Background: Diagnosis of axial spondyloarthritis (axSpA) is often delayed, with an estimated time to diagnosis of 6 years ${ }^{1}$ leading to patient (pt) anxiety and difficulties in coping with daily life. Many fears and beliefs have been identified, ${ }^{2}$ including unpredictability of the disease course and concerns for the future. A survey revealed that $61 \%$ of pts want to share such experiences with other pts. ${ }^{3}$ Objectives: The goals were to: 1) create a video program to help pts share experiences and promote coping strategies; 2) establish the program on the internet and social networks; 3 ) assess the usefulness of the program for pts and healthcare professionals (HCPs).

Methods: Clefs de dos is a national French program initiated in 2015. It is led by a pt organisation, ACS-France (Action Contre les Spondyloarthropathies), Catalpa (conducted interviews, made visuals) and UCB Pharma (co-creation and promotion). Pts with axSpA were recruited by ACS on a voluntary basis to participate in focus groups; pts were selected according to their level of disease acceptance (denial [Gp1] or acceptance [Gp2]). 4 steps were planned: 1) Gp1 focus group interviews to collect feelings, words and voices; 2) Gp2 interviews to describe the pt pathway and stages in the process of disease acceptance; 3) face-to-face Gp1+Gp2 meetings for pts to share their own experiences and confront their own views; 4 ) rheumatologist interviews to evaluate the impact of pt testimonies on their own practice.

Results: 13 axSpA pts (10 Gp1, 3 Gp2) participated, aged 25-65 years (yrs), with 5-17 yrs disease duration; 10 were female. An animated visual was produced using Gp1 pt interviews; analysis revealed feelings of loss prior to diagnosis. Photographs and audio testimonies were used to create 3 documentary portraits of Gp2 pts, illustrating the process of disease acceptance and acquisition of coping skills (Figure). Videos of Gp1+Gp2 meetings emphasised interpersonal help and counselling between pts. 3 rheumatologists participated in step 4. They identified the importance of pt interaction to develop positive strategies, pt perspective and removal of barriers in the physician-pt relationship, and use of videos in self-management programs. By December 2016, $>5,000$ people had visited the website (www.clefsdedos.com), with $\sim 500$ Facebook followers from March-December 2016 (www.facebook.com/Clefsdedos/) reaching 30,000 people via link sharing.

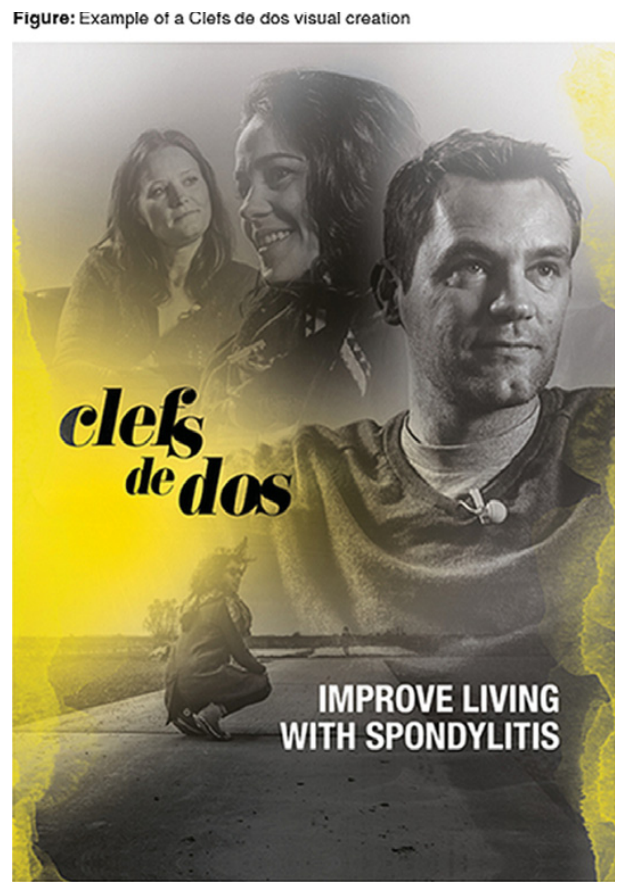

Conclusions: Clefs de dos was developed by and for axSpA pts. The program answers unmet needs by sharing pt experiences, particularly in situations of delayed diagnosis and lack of disease acceptance. Online access reflects good acceptability of the program, which can also be used as an educational tool in self-management. The next step is to involve other HCPs (eg. nurses, physiotherapists, psychologists).
References:

[1] Wendling D. Joint Bone Spine 2014;81(1):6-14.

[2] Berenbaum F. PLoS One 2014;9(12):e114350.

[3] Bolla G. Presentation O13, SFR 2014; Paris, France.

Acknowledgements: The authors acknowledge all patients who participated in the Clefs de dos program, and L Epivent and A Martra for contributions in co-building the communication plan. This program was conducted in partnership with ACS-France and Catalpa, and co-created and funded by UCB Pharma. Disclosure of Interest: C. Beauvais Speakers bureau: UCB Pharma, C. Sordet: None declared, A. Leboime: None declared, D. Vandame Employee of: UCB Pharma, C. Saadoun Employee of: UCB Pharma, G. Genin: None declared, F. Gerald: None declared

DOI: 10.1136/annrheumdis-2017-eular.1987

\section{OP0065 NURSE-LED VACCINATION PROGRAM DRAMATICALLY IMPROVES PNEUMOCOCCAL VACCINATION COVERAGE AMONG PATIENTS WITH CHRONIC INFLAMMATORY RHEUMATIC DISEASES: A PROSPECTIVE PILOT STUDY}

T. Goulenok, J. Serre, C. Francois, M.-C. Van der Haegen, J.-F. Alexandra, T. Papo, K. Sacre. Paris-7 University, APHP, Bichat Hospital, Paris, France

Background: Patients with chronic inflammatory rheumatic diseases (IRD) receiving immunosuppressive therapy are at high risk for invasive pneumococcal disease. Despite national recommendations regarding pneumococcal vaccination, vaccination rate remains low in this population.

Objectives: We aimed to determine whether a nurse-led vaccination program improve pneumococcal vaccination coverage among patients with chronic IRD. Methods: From April to August 2015, all consecutive adult patients with a chronic IRD admitted in our day hospital unit (Department of Internal Medicine, Bichat Hospital, Paris, France) were screened. Eligibility for pneumococcal vaccination was assessed according to French national recommendations. Patients were identified as candidate for pneumococcal vaccination, informed on the benefice and risk of vaccination and vaccinated by nurses. Pre-intervention (i.e. percentage of patients candidate for vaccination vaccinated before the intervention program) and post-intervention (i.e. percentage of patients candidate for vaccination vaccinated after the intervention program) pneumococcal vaccination rate were compared using Chi2 test.

Results: 126 consecutive patients (43 [24-89] years, 61.9\% females) with a chronic IRD were admitted in our day hospital unit during a 4 months period. Among them, $76(60.3 \%)$ patients were candidate for pneumococcal vaccination because receiving prednisone, immunosuppressive drugs and/or biotherapy. The pre-intervention pneumococcal vaccination rate was $17.1(13 / 76)$ $\%$. Among patients candidate for pneumococcal infection but not vaccinated $(n=63), 56(88.9 \%)$ were accurately identified by nurses. Ten patients refused to be vaccinated and 46 eventually received pneumococcal vaccination. The post-intervention pneumococcal vaccination was $77.6(59 / 76) \%(p<0.001$ as compared to the pre-intervention rate).

Conclusions: Nurse-led vaccination program dramatically improves pneumococcal vaccination coverage among patients with chronic IRD.

Disclosure of Interest: None declared

DOI: 10.1136/annrheumdis-2017-eular.2706

\section{OP0066 THE PROBLEM BASED LEARNING APPLIED TO TEACHING RHEUMATOLOGICAL TOPICS AMONG NON RHEUMATOLOGY RESIDENTS}

C.A. Guillen-Astete $^{1}$, A. Braña-Cardeñosa ${ }^{2}$, M. Zamorano-Serrano ${ }^{2}$, P. Gallego-Rodriguez ${ }^{2}$, C. De la Casa-Resino ${ }^{2} .{ }^{1}$ Rheumatology Department; ${ }^{2}$ Urgency Department, Ramon y Cajal University Hospital, Madrid, Spain

Background: Many pedagogical models have been included to the teaching strategies available in almost all fields of knowledge in the last 20th years. In the field of medicine teaching, the traditional teaching (TT) model based on an expert speech aid by a multimedia slide projection is now only one of many strategies. One of them is the Problem-Based learning (BPL) model, which is one of the most applied in undergraduate education; however the documented experience on residents education with rheumatologic contents in Spain is inexistent. BPL model consist in a lecture based in a clinical case or cases that the students must affront using several tools, most of them provided previously by the teacher, and the opinion of their classmates. Groups are encouraged to try to solve the medical problem while the teacher leads debates among the groups.

Objectives: Our goal is to test the impact of PBL model compared to TT among non rheumatology residents who participated in an rheumatology educational program using long term measures in their clinical practice.

Methods: We developed an educational program for second year residents of all medical specialties in our teaching hospital. The topic included the assessment and treatment of lumbar acute pain and was programmed in two separated dates using both the TT and PBL models. Students were unaware of the teaching strategy. Contents of both courses were the same and were prepared by two different experts. We reviewed the registries of medical attention performed by all residents for patients who consulted due to acute lumbar pain, and collected data about three aspects: Adherence to image test recommendations (AITR), 